\title{
STRUCTURAL SOCIAL CAPIT AL AND KNOWLEDGE ACQUISITION: IMPLICATIONS OF CLUSTER MEMBERSHIP
}

\author{
Pedro M. García-Villaverde \\ Universidad de Castilla-La Mancha \\ Gloria Parra-Requena \\ Universidad de Castilla-La Mancha \\ F. Xavier Molina-Morales \\ Universitat Jaume I de Castelló
}

\begin{abstract}
This paper analyzes the implications of belonging to a cluster through the relationship between structural capital and knowledge acquisition. Findings suggest structural social capital affects only indirectly to the knowledge acquisition through the relational and cognitive dimensions for firms member of the cluster. However, structural dimension also maintain a direct impact on knowledge for the external firms. This paper contributes to the cluster literature a better contextualization and understanding of the relation between the structural social capital and knowledge acquisition. In addition, paper also contributes to consolidate the inter-organizational approach to social capital theory in order to understand how and in which context the social capital dimensions are interrelated. Paper analyzes how firms can acquire valuable knowledge from their networks, overcoming the gap of the literature on how this process occurs inside and outside the clusters. Study proposes some recommendations for companies and institutions, and new complementary lines of research.
\end{abstract}

Palabras clave:

Social capital, knowledge acquisition, cluster, proximity, social networks. 


\section{STRUCTURAL SOCIAL CAPITAL AND KNOWLEDGE ACQUISITION: IMPLICATIONS OF CLUSTER MEMBERSHIP}

\section{INTRODUCCIÓN}

There is now increasing attention to the social or relational capital perspective on the strategic and organizational disciplines (Ahuja, 2000; Rowley, Behrens and Krackhardt, 2000; OwenSmith and Powell, 2004). In short, it is assumed that this form of capital provides firms with external sources of information and knowledge, having a significant effect on firm value creation (Nahapiet and Ghoshal, 1998) and in consequence affecting to firms' innovation and performance (Adler and Kwon, 2002; Lorenzen, 2007).

In spite of the proliferation of research on this particular field, some relevant issues have been missed or underestimated, in our opinion. Particularly, geographical proximity between actors becomes relevant in this regard and should be considered Vittoria \&Lubrano Lavadera 2014. For instance, we can expect that proximity reduces the costs of ongoing relationships and increases the frequency of personal contacts that build social relations between individuals and organizations, thereby facilitating the flow and transfer of knowledge in a local context (Rosenkopf and Almeida 2003; Li, Ye and Sheu, 2014).

In our case we have focused on the membership / non-membership of the firm to one cluster in order to capture proximity between actors. Moreover, we aim to analyze the interactions between social capital dimensions (Othmar M. Lehner 2014; Robert Huggins \& Andrew Johnston (2010).and how they influence on knowledge acquisition of the firms comparing inside and outside the cluster locations Aslesen \& Harirch 2015 . We agree that in spite of previous research assumptions, concerned on the intra-firm relationships (e.g. Tsai and Ghoshal, 1998), we take into account to interrelations between the social capital dimensions on inter-organizational relationships.

Specifically, our expected contribution suggests that structural dimension of the social capital, which has probably the most unpredictable effect, exerts a differentiated role for cluster internal and external firms on accessing to knowledge sources. The structural dimension that refers to the overall pattern of connections between actors in the network (Greve and Salaff, 2003; Nahapiet and Ghoshal, 1998), affects only indirectly to the knowledge acquisition for firms member of the cluster through the two dimensions of the social capital. On the contrary 
the structural dimension also exerts a direct impact on knowledge for the external firms. These findings may contribute both to networking and cluster literatures improving our understanding of how firms acquire knowledge and the influence that proximity between firms exerts in this process.

We gathered data for this study from a questionnaire survey on a country-wide sample of 224 Spanish companies in the footwear industry. This industry can be considered as a mature, traditional industry with a significant presence of the industrial clusters, being particularly suitable to study the proposed questions.

The paper has been structured as follows. First, we explain the main concepts and grounding and justifying the hypotheses. Then we describe the design of the empirical study and expound the findings. Finally, the paper proposes a number of conclusions, underlining the contribution and further implications of this research.

\section{THEORETICAL FRAMEWORK}

\subsection{Relational perspectives and industrial cluster}

There is now an increasing attention to the social or relational capital perspective on the strategy and management disciplines (Rowley et al., 2000; Ahuja, 2000; Owen-Smith and Powell, 2004). It is assumed that this form of capital provides firms for external sources of information and knowledge, having a significant effect on value creation (Nahapiet and Ghoshal, 1998) affecting to firms' innovation and performance (Adler and Kwon, 2002; Lorenzen, 2007; Molina-Morales and Expósito-Langa, 2012).

Contexts of geographical proximity such as those defined as industrial clusters or districts (Becattini, 1990; Porter, 1998) include a wide range of experiences in different industries, countries and at different technological levels (see, for example, Tallman, Jenkins, Henry and Pinch, 2004; Inkpen and Tsang, 2005).

In order to overcome previous uniform conception of a cluster, authors has assumed the heterogeneity of companies and organizations involved in these locations (Boari and Lipparini, 1999; Lazerson and Lorenzoni, 1999; Giuliani, 2011; Munari, Sobrero and Malipiero, 2012). Companies in cluster have distinctive individual attributes (Boschma and Ter Wal 2007). These attributes will determine the differences between companies in the 
cluster when it comes to exploiting the advantages of the location (Giuliani and Bell 2005; in Spain Hervas-Oliver and Albors-Garrigós, 2012). And indeed the opportunities and constraints generated by the location in the cluster are also unevenly distributed among its members (Giuliani, 2007)

A special mention deserves the studies of clusters that have taken as theoretical basis the socalled social or relational capital. This perspective focuses on the relationships and interactions between the various actors in the network, placing the source of the benefits accruing to organizations in the clusters in this relational field. Several studies suggest that geographic proximity and interaction between individuals or companies favor the generation of social capital (Coleman, 1990; Boland and Tenkasi, 1995 McKeever et al, (2014). Moreover, a cluster may be identified as a category of strong-tie network with intense, frequent and close relationships among its members. In fact, it is frequently argued that this category of network provides substantial benefits for the companies involved in terms of flow of knowledge (Uzzi, 1996).

The clusters are considered as inter-organizational networks which generate relations called social bonded capital (bonded values: trust, cohesion, etc.) are combined with relationships that generate the bridging capital and seeking bridging opportunities and access to new and exclusive external resources (McEvily and Zaheer, 1999; Molina-Morales \& MartínezFernández , 2006 or Besser \& Nancy Miller, 2011). In particular, relational assets associated with access to sources of knowledge and knowledge to create value and improve the innovation from the company (Molina-Morales and Martinez-Fernandez, 2009).

One relevant application of this relational perspective is to analyze both network level and the individual and their interactions from the effects of moderation and mediation (BelsoMartinez et al., 2011). In order to overcome previous uniform conception of a cluster, authors has assumed the heterogeneity of companies and organizations involved in these located (Boari and Lipparini, 1999; Lazerson and Lorenzoni, 1999; Giuliani, 2011; Munari et al, 2012). Companies in cluster have distinctive individual attributes (Boschma and Ter Wal 2007). These attributes will determine the differences between companies in the cluster when it comes to exploiting the advantages of the location (Giuliani and Bell 2005; in Spain Hervas-Oliver, and Albors-Garrigós, 2012). And indeed the opportunities and constraints generated by the location in the cluster are also unevenly distributed among its members (Giuliani, 2007; Raphael Suire \& Jerome Vicente (2014)). 
Additionally, different subnets within the cluster were identified and analyzed, including the information network, the network of technological knowledge and other, so that each of these flows affect a specific group of players and so also uneven (Breschi and Lissoni 2001, Lissoni 2001; Boschma and Frenken, 2006, among others). In similar terms Rabellotti and Morrison (2005) talk about the concepts of core and periphery networks in the cluster (in Spain, Molina-Morales, Martínez-Fernández and Coll-Serrano, 2012), to differentiate between subnets with high intensity of relations and the connected periphery outside the cluster. Finally, another line of analysis has been to distinguish between internal and external relationships identified as local and global buzz pipelines, where the first network requires proximity to external contacts of the overall pipelines (Bathelt et al, 2004; Valdaliso et al, 2011).

\subsection{Social capital: interdependent dimensions}

Since social capital has become an "umbrella concept" we used the definition provided by Nahapiet and Ghoshal (1998: 243), who considered social capital as the sum of current and potential resources inserted in, available through and derived from the network of relationships possessed by a social unit. According to the social capital perspective actors (individuals, organizations or communities) are benefit from value provided by the networks of relationships. As a result actors may exploit for their benefit resources inserted into such relationships (Rampersad, Quester and Troshani, 2010). As a consequence social capital has been view as an explanatory factor of the advantage of organizations (e.g. Dyer and Singh, 1998).

Social capital is a multidimensional concept since should be addressed from different perspectives Othmar M. Lehner 2014; Robert Huggins \& Andrew Johnston (2010). Nahapiet and Ghoshal (1998) distinguished three dimensions: structural, relational and cognitive which correspond respectively to architecture of the whole network and the strength and nature of the ties in network. As Bolino, Turnley and Bloodgood (2002) argued this distinction is adequate for an analysis at the organizational level in contrast with others more approximated for the individual levels (Granovetter, 1973; Burt, 1992; Seibert, Kraimer and Liden, 2001).

The structural dimension covers the interaction of the social network, focusing on the properties of the social system and the network of relationships as a whole. Structural dimension also emphasizes the values of the information and control advantages provided by 
the structural position of the firm in the network (Burt 1992; Granovetter 1973, 1985). Among the most relevant aspects of this dimension can be underlined the existence of network ties between agents and actors, the network configuration and the appropiability issue.

The relational dimension analyzes the characteristics and attributes of relationships between agents or actors in the network, which are mainly derived from the company's history and reputation (Granovetter, 1992; Gulati, Nohria, \& Zaheer, 2000). This dimension is focused on characteristics of the relations between actors regarding some relational assets as trust, norms, obligations, solidarity and so on. Trust is probably the most important relational asset of the social capital. Trust between different actors and organizations basically refers to the certainty that other agents in the network will not act opportunistically (Barney and Hansen, 1994, Bhattacharya, Devinney and Pillutla, 1998).

The cognitive dimension represents the resources provided by the understanding and the meaning shared among members of the network (Nahapiet and Ghoshal, 1998: 244).The cognitive social capital facilitates a shared vision of collective goals and aims (Tsai and Ghoshal, 1998). In fact, common culture and shared goals between members of the network are the key concepts of this dimension (Inkpen and Tsang, 2005). Shared goals represent the degree to which network members share a common understanding and approach to the achievement of the tasks and results (Inkpen and Tsang, 2005). On the other hand, the shared culture refers to the degree to which the norms of behavior conduct relations, that is the set of rules and institutionalized rules that guide appropriate behavior in the network (Gulati et al. 2000: 205).

Finally, it must be mentioned, that social capital dimensions are not independent each other. Indeed all social dimensions can be considered as highly interdependent as some previous research agreed (Mael and Ashforth, 1995; Butler and Purchase, 2008, Westerlund and Svahn, 2008; Castro and Roldán, 2013; Hsu and Hung, 2013).

\subsection{Cluster, social capital and knowledge acquisition}

Knowledge acquisition has become as a key element to the success of firms (Weber and Weber, 2007; Svare et al, 2015). Knowledge acquisition refers to the process by which firms obtain knowledge. The activities responsible of the acquisition of knowledge by organizations include the internal creation of knowledge, experimental learning and external knowledge (Huber, 1991). External sources of valuable knowledge are the most sources (Li, Poppo and 
Zhou, 2010). External sources include a great range of actions related to the knowledge exchanges with other actors in the environment (workshops, benchmarking practices, interaction with other actors, or even establishing strategic alliances).

Companies cannot internally generate all the knowledge they need to face a complex and changing environment. Therefore, companies have to seek external sources of knowledge through their relationships with suppliers, customers, competitors, institutions, etc. to create opportunities to acquire and exploit external knowledge (Lane and Lubatkin, 1998). The relevancy of the external knowledge acquisition is supported by the idea that flows of knowledge are needed to improve the innovative capacity of firms (Dyer and Singh 1998; Chen and Huang 2008), or even firms' performance as some studies have shown (Yli-Renko, Autio and Sapienza, 2001; Weber and Weber, 2007).

Intense interorganizational relationships, which are involved in geographical proximity, are regarded as a driver of a broad range of knowledge sources (Presutti et al., 2013). Physical proximity increases the probability of collaboration (Correia and Petiz, 2007) and facilitates technical and market information exchanges among co-localized firms (Boschma and ter Wall 2007). Proximity produces spontaneous social and professional interactions among entrepreneurs and employees in the industry, which facilitate knowledge diffusion (Lazerson and Lorenzoni 1999). Thus these interactions channel intangible resources such as knowledge (Warren, Patton and Bream 2009). Particularly, tacit or uncodified knowledge transmission requires intense interactions (Dyer and Nobeoka 2000) and therefore knowledge is more easily spread in face-to-face contacts (Uzzi 1996).

\section{HYPOTHESES}

\subsection{Structural social capital and knowledge acquisition}

Social capital facilitates acquisition, integration, recombination and release of resources for firms (Coff and Blyler, 2003). More specifically the strength of ties and network's density structural social capital- provide access to numerous information sources and improve the quality and relevance of the acquired knowledge (Adler and Kwon, 2002).

Particularly, dense networks are suitable structures for learning through interaction and exchange of tacit knowledge resources between agents. Thus, companies into strongly interconnected networks can better exploit the existing opportunities and shared information 
and knowledge in collaborative exchanges (Parra-Requena, Ruiz-Ortega and GarcíaVillaverde, 2013).

In addition, structural social capital provides channels for firms for information flows and an optimal context for resource exchanges and in consequence for gaining access to valuable information (Burt, 1992; Nahapiet and Ghoshal, 1998). In fact, network members should establish a structure with dense interactions in order to exchange more reliable information and resources (Tsai and Ghoshal, 1998; Villena, Revilla and Choi, 2011). In short, frequent social interactions allow network members to learn more about each other and to exchange more important and valuable information ( $\mathrm{Li}$ et al, 2014).

Despite of the advantages of structural social capital in order to acquire relevant and knowledge related to innovation, several authors agreed that excessive interaction between agents of a network can cause redundancy in the exchanged information (Koka and Prescot, 2002). Moreover, in a dense network with frequent interactions, firms usually focus on their close contacts, omitting those agents outside the network (Inkpen and Tsang, 2005).

In general, in spite of diversity in argumentations and findings, it is expected that companies with greater structural social capital can acquire much more knowledge resources. We focus on the association between the structural social capital with relational and cognitive dimensions (Tsai and Ghoshal, 1998; Li et al, 2014), and geographical context in which to locate the companies (Pulles and Schiele, 2013).

\subsection{The mediating role of relational social capital and cognitive social capital}

Several authors claimed the role of links between the dimensions of social capital in order to deepen in the controversial effect of structural social capital on knowledge acquisition (Tsai and Ghoshal, 1998). Butler and Purchase (2008) pointed out that each dimension of social capital builds or affects on the other dimensions. Specifically, Castro and Roldan (2013) suggested that the structural dimension is the key since it generates the other components of social capital and influences in their formation and development. We suggest that relational and cognitive dimensions of social capital are complementary each other and lead to structural social capital to new and relevant external knowledge.

The role of relational social capital 
Tsai and Ghoshal (1998) emphasized the influence of structural capital in the development of relational capital. The structural configurations can boost confidence and reliability perceived by the agents of the network because trusting relationships arising from social interactions (Granovetter, 1985). So, as two agents interact with each other over time, it increases the strength of their ties and the agents are perceived as trustworthy (Gabarro, 1978; Gulati, 1995; Tsai, 2001; Castro and Roldan, 2013). Therefore, frequent social interactions allow players know each other much better and build confidence between them to share important information (Gulati and Gargiulo, 1999). Li et al (2014) highlight that social interaction is a prerequisite to the creation of trust. In fact, cooperation and the mutual behavior during social interaction processes contribute to enhance the level of trust.

The relational social capital of the firm favors the acquisition of relevant and innovative knowledge. Confidence plays a key role in the will of the actors in the network to transfer confidential information and valuable knowledge (Doz, 1996; Gulati, 1995; Koka and Prescott, 2002; Parra-Requena et al., 2013). Li et al. (2014) argued that network members tend to keep private information, for their own benefit. Frequently, they do not want to share proprietary information, because of free-riding of information leaks risks. However, trust discourages opportunistic behavior of agents and promotes the exchange and combination of knowledge (Inkpen and Tsang, 2005; Eapen, 2012; Castro and Roldan, 2013). Thus, a trusting relationship encourages greater strategic-level information sharing network among members and further enhances the benefit of information sharing (Fawcett et al., 2006; Li et al, 2014).

As noted previously, structural social capital tends to generate relevant knowledge exchange between agents in the network. However, external knowledge can be limited and to some degree redundant for the negative effects of excessive interaction with network members (Koka and Prescot, 2002; Inkpen and Tsang, 2005). We think that these negative effects can be avoided thanks to trust. Thus, if firms take advantage of their strongly interconnected networks to create trust with key members of the network, will have access to confidential information and valuable knowledge. Relational social capital allows and encourages an intense flow of information and knowledge, channeling the potential benefits of structural social capital (Carey, Lawson and Krause, 2011).

\section{The role of cognitive social capital}

The frequent and intensive interaction firms are important mechanisms for establishing higher levels of mutual understanding (Leuthesser, 1997, Pulles and Schiele, 2013). Tsai and 
Ghoshal (1998) point out that social interaction plays an important role in setting common goals and values between the different agents of a network. Thus, the structure of social interactions influences the formation of a shared vision between agents. Network members can share culture, codes, values and practices through their strong social interaction. Moreover, strong ties and dense interactions for shared vocabulary and language between network members (Mael and Ashforth, 1995). The social interaction process can also generate new sets of visions based on common interest and mutual understanding ( $\mathrm{Li}$ et al, 2014; Yim and Leem, 2013). In short, structural social capital favors the development of cognitive social capital.

Knowledge can be communicated, transferred and acquired more efficiently between firms with similar reference structures (Knoben and Oerlemans, 2006). When actors are involved in the same network, share values and vision, to have similar perceptions on how to act with each other and promote mutual understanding and tend to exchange valuable knowledge (Tsai and Ghoshal 1998). However, cultural conflicts and the lack of coherence in organizational mission limit knowledge acquisition and inter-organizational learning (Simonin 1999). Therefore, the more members share their networks objectives, expectations and culture, more valuable knowledge will be transferred and acquired (Mowery et al., 1996). Chiu et al. (2006) noted that shared vision will help network members to understand the benefits of knowledge sharing, and, in turn, it will increase the quantity and quality of shared knowledge. According to this approach, cognitive social capital provides companies access to relevant external knowledge.

Consequently, cognitive social capital plays a main role in leading the structural capital to the acquisition of knowledge. On one hand, network firms with strong ties and dense interactions can share their language and vision, avoiding possible misunderstandings in communications (Li et al., 2014). On the other hand, network members who share a vision can detect higher potential value in knowledge exchange and will be more favorable to intensify knowledge exchange (Pulles and Schiele, 2013). Thus, network members which are able to take advantage of strong ties and dense interactions to share values, culture and vision with their contacts will acquire more new and relevant information and knowledge. In short, structural social capital will allow firms to access key network knowledge thought their cognitive social capital. 


\subsection{Which are the industrial cluster's belonging implications}

The literature of geographical agglomeration highlights strong implications of physic proximity on the development of social capital and their effects on knowledge exchange (eg Muscio, 2006; Boschma and ter Wall, 2007; Molina-Morales and Martinez-Fernandez, 2008; Warren et al, 2009; Molina-Morales and Expósito-Langa, 2012). Thus, geographical proximity is becomes a key factor that affects the intensity and prevalence of each type of social capital effect. We focus on how the firm's membership to an industrial cluster influences on the above structural social capital effects.

Several studies argue that a spatially concentrated configuration allows a greater exchange of information between co-located firms (Utterback 1974; Jaffe, Trajtenberg and Henderson 1993; Panicia, 1998; LeSage and Fisher, 2012). In fact, knowledge transfer between companies in the cluster is one of its major externalities (Krugman 1991), since industrial clusters can act as accelerators of the dissemination of knowledge for several reasons (Brenner 2001). First, when knowledge is at individual ability level, the learning process can occur only through interaction and observation. Then, geographical proximity between firms facilitates the transfer process since it will be possible to establish a greater number of personal contacts. Second, local institutions in clusters provide supporting services to the companies in the region, since they gather and spread knowledge among firms, thereby reducing search costs (Molina-Morales 2005). Third, the mobility of employees in an industrial cluster is also another of the chances for the exchange of information (DeCarolis and Deeds 1999).

In consequence, clustered firms have advantages in accessing large semipublic knowledge, which is "in the air" in the "industrial atmosphere" of the clusters (Marshall, 1890). However, an important "dark side" of structural social capital also emerges on industrial clusters. Family, social and professional ties of clusters actors facilitate the formation of a dense network but also the overlapping links (McEvily and Zaheer, 1999) and the paradoxes of the network appear (Hakanson and Ford, 2002). Thus, dense networks with strong ties may worsen the problems of redundancy, lock-ins, isolation from external world and myopia of clustered firms (Gargiulo and Benassi, 2000; Koka and Prescott, 2002; Inkpen and Tsang, 2005).

In this context, we think, structural capital does not allow direct access to new information and relevant knowledge to the clustered firms, since that disadvantages of overdensity of 
networks and strength of ties are accentuated. Therefore, the development of structural social capital is not enough to access valuable information and knowledge. Thus, within clusters, only companies which exploit density and strength to develop trust and shared values with their contacts will be able to acquire relevant knowledge. Therefore, we can say that structural social capital has only an indirect effect, through the relational and cognitive social capital, on knowledge acquisition. Consequently we expect a total mediator effect of both relational and cognitive social capital in the relationship between structural capital and acquisition of knowledge of the companies located in industrial clusters. These arguments allow us to define the following hypothesis:

H1 For the clustered firms, structural social capital only exerts an indirect effect on the knowledge acquisition through the relational and cognitive social capital.

In the case of firms located outside clusters, they have more difficulties in accessing to relevant semipublic knowledge through informal relations those which are based on geographical proximity. Therefore, firms outside industrial clusters rely more on social capital that can generate with their networks, in any dimension to obtain valuable external knowledge.

Within geographical context is much more difficult that disadvantages of the so-called paradoxes appear (Hakanson and Ford, 2002). Furthermore, membership of dense and strongly interconnected networks is particularly relevant to exploit opportunities and share information and knowledge in cooperative exchanges. According to these arguments, firms outside the industrial clusters holding high levels of structural social capital are able to acquire new and valuable knowledge (Lane et al, 2001). Thus, structural social capital becomes a key factor to acquire external knowledge for those external cluster firms, which cannot easily access it by interactions "face to face" through personal relationships (Audretsh, 1998). Therefore, we expect a significant direct effect of structural social capital on the acquisition of knowledge in clusters outside firms.

On the other hand, the strength and density of relationships between the firms and their contacts also promote greater trust between the agents, giving them access to confidential information and valuable knowledge ( $\mathrm{Li}$ et al, 2014). Thus, the relational social capital is a driver of the structural capital of external clusters firms towards the acquisition of knowledge. Also, social interaction with contacts promotes the development of values and a shared 
culture that make much easier to transfer and acquire (Chiu et al, 2006). From this perspective, the cognitive social capital provides a way to lead the structural social capital towards the acquisition of knowledge. We propose that when firms cannot take advantage of agglomeration benefits of belonging to an industrial cluster, structural social capital becomes a key factor to access valuable tacit knowledge either directly or through the relational and cognitive social capital.

In summary, for firms located outside the clusters, the density and strength of relationships allow them access directly and indirectly, through the development of greater level of trust and shared values with contacts to new and valuable knowledge. Therefore, in outside cluster contexts coexist the direct effect of structural social capital on the acquisition of knowledge with indirect effects generated through the relational and cognitive social capital. From these arguments, we can establish the following hypothesis:

H2 For the external cluster firms, structural social capital exerts direct and indirect effects on the knowledge acquisition through the relational and cognitive social capital.

\section{METHOD AND EMPIRICAL SETTING}

\subsection{Sampling}

The empirical study has been developed on the Spanish footwear industry. Since it is a labour intensive industry it is characterized by the predominance of small and medium firms. This industry is also characterized by the concentration of its firms in Spanish regions with a high tradition of shoemaking. The Valencian Community is the region with the highest number of firms (66 percent), followed by Castilla-La Mancha (10 percent), La Rioja (7 percent) and the Balearic Islands (3.55 percent), among others. Furthermore, the high concentration of firms in certain areas allow us to identify 30 industrial clusters in this industry, as mapped by Boix and Galletto (2006). We consider that this industry is appropriate for our research proposals since its geographical distribution of firms allow us to compare between firms located in industrial clusters with isolated firms. In addition, social capital needs time to develop and footwear industry is a mature and highly competitive industry so it is the optimal scenario to analyze social capital as well as aspects related to the knowledge transfer. Our analyses focus on the particular context of a low-tech industry (Hervas-Oliver, J.L. and Albors-Garrigos, J. 2012) 
In order to establish the population of firms we used two databases $-\mathrm{SABI}^{1}$ and Camerdata ${ }^{2}$, we completed this information with the information of the main Spanish footwear-industry associations as AICE (Asociación de Industrial del Calzado de Elche) and AIDECA (Asociación de Innovación y Desarrollo Empresarial del Calzado en Almansa). We proposed the condition not to include firms with fewer than five employees in order to configure our database. This criterion have been proposed in previous works in the field of industrial cluster and business management (Spanos and Lioukas, 2001; Boschma and Ter Wall, 2007; ParraRequena, Molina-Morales and García-Villaverde, 2010). This is because a minimal operative structure is required to define the behaviour's firms. Once duplicated cases were eliminated, we obtain a population of 1,403 firms. We sent a questionnaire ${ }^{3}$ among the CEOs of these firms and we obtained 224 valid complete questionnaires, it represents a response rate of $16.97 \%$, with a confidence level of $95 \%$ and a sampling error of $5.96 \%$. Of the 224 firms, 166 are located in industrial clusters. According to Becattini (1979) firms in industrial clusters have a greater sense of belonging ${ }^{4}$ than firms located outside. We observed that firms in industrial clusters show a greater feeling of belonging (5.13) than firms located outside (3.69). We developed an ANOVA test for social capital dimensions and knowledge acquisition variables between the firms that answered to the first and second sending. This test not reveals any significant differences in any of the analyzed variables. Furthermore we observed no differences between the population and our sample on structural characteristics as size and age, so a non-response bias was not detected (Armstrong and Overton, 1977).

\subsection{Variables}

Cluster membership: We used the location of the firms in order to identify firms belonging to industrial clusters. When a firm was located in one of the industrial clusters detected by Boix and Galleto (2006), it was designated as a firm belonging to an industrial cluster.

Structural social capital: We have used a second order construct in order to measure the structural social capital. This construct is formed by two first order constructs -network ties

\footnotetext{
${ }^{1} \mathrm{SABI}$ is a directory of Spanish and Portuguese firms that provides general information and financial data. In the case of Spain, it compiles information from the 17 Spanish regions on more than 95 percent of the firms with total yearly revenues over $360,000-420,000 €$.

2 The Camerdata database compiles a directory of all Spanish firms from the network of local Chambers of Commerce.

${ }^{3}$ The information was gathered between October (2007) and January (2008).

${ }^{4}$ In order to measure the feeling of belonging, we included in the questionnaire an item in which managers had to mention the level of agreement or disagreement with the following statement: In general, Ifeel identified with my local companies.
} 
and network configuration-. We used the three item-scale of Maula, Autio, and Murray (2003) to measure network links. We used network density as the key factor to measure network configuration. In this case we used a three-item scale used in recent studies by Parra-Requena et al. (2013) that was adapted from Molina and Ares (2007) and Exposito-Langa and Molina (2010). The results show the high reliability of this second order construct.

Relational social capital: We used trust to come closer to this dimension of social capital. After analyse different studies (e.g., Tsai and Ghoshal, 1998; Kale, Singh and Pelmutter, 2000; Yli-Renko et al., 2001), we decided to use the scale of Kale et al. (2000) for two reasons. First, as Ruiz-Ortega, Parra-Requena and García-Villaverde (2013) pointed out this scale is considered the most comprehensive for its application to the external networks of companies. Second this scale has been used in recent literature (Kohtamäki, Vesalainen, Henneberg, Naudé and Ventresca, 2012).

Cognitive social capital: In order to measure this dimension of the social capital we used a second-order construct formed by two first-order constructs -shared goals and shared culture. We used a six-items scale to measure shared goals comprised of the adaptation to the characteristics of our study of the items used in the studies of Tsai and Ghoshal (1998), Young-Ybarra and Wiersema (1999), Yli-Renko et al. (2001), and Carson et al. (2003). With regard to shared culture, we used the two items scale from Simonin (1999). As in the case of structural social capital, this second order construct shows high reliability.

Knowledge acquisition: In order to measure this variable we revised the precedents in the literature, after that we consider that the Kale, Singh and Pelmutter (2000) and Maula, Autio and Murray (2003) are the most suitable for our study. This scale has been used in ParraRequena et al. (2010). We adapted these scales to our specific context since they were used in the field of strategic alliances and customer relationships. This construct allows us to measure knowledge acquisition of firms derived from their relationships with their contacts. This construct includes knowledge acquisition about competition, trends, customer needs and technical issues. In this line, it includes the acquisition of key information for critical capabilities of the firms. This kind of knowledge is fundamental for firms' competitiveness (Teece, Pisano and Shuen, 1997; Spanos and Lioukas 2001).

Control variables: In this study we included three control variables; age, size and type of shoes. Firm age was measured by the number of years from the creation of the firm to the survey date. Size was measured by the number of employees of the firms at the moment of the 
survey. We consider that is interesting analyse the type of shoes since each type of shoes sector can affect the process of behaviours of companies because each one has particular characteristics and different competitive conditions (Bremmers, Omta, Kemp and Haverkamp, 2007). We used this classification: female, male, specialized, children and diversified.

\subsection{Analysis techniques}

We used Partial Least Squares (PLS) to test the hypotheses. This technique is particularly recommended for testing mediation hypotheses (James, Mulaik and Brentt, 2006). Furthermore, PLS has a suitable analysis technique adequate for small samples and places minimum requirements on both measurement scale and multivariate normality (Chin 1998; Hulland 1999). We used PLS-Graph 3.0 software and a bootstrap re-sampling procedure of 500 sub-samples to determine the coefficients' statistical significance.

\section{RESULTS}

\subsection{Measurement model}

In order to evaluate the measurement model, we have to study individual reliability, composite reliability, convergent validity and discriminant validity. With regard to the reliability of the items, all loadings $(\lambda)$ show values higher than the recommended threshold of 0.707 (Carmines and Zeller, 1979). In order to test construct reliability we have to use composite statistic of reliability $\left(\rho_{c}\right)$ which is similar to Cronbach's alpha. As we can observe in table 1 and 2, all the constructs are greater than 0.8 so we can confirm the strict reliability of the constructs used in our study (Nunnally, 1978). To evaluate the convergent validity we analyze AVE (Average Variance Extracted). The results show high convergent validity since all values are higher than this recommended threshold of 0.5 (Fornell and Larcker, 1981).

Table 1. Scale reliability and Convergent validity inside clusters

\begin{tabular}{|l|c|c|}
\hline \multicolumn{1}{|c|}{ Construct } & Composite reliability & AVE \\
\hline Structural Social Capital & 0,888 & 0,799 \\
\hline Relational Social Capital & 0,917 & 0,688 \\
\hline Cognitive Social Capital & 0,881 & 0,789 \\
\hline Knowledge Acquisition & 0,949 & 0,755 \\
\hline
\end{tabular}


Table 2. Scale reliability and Convergent validity outside clusters

\begin{tabular}{|l|c|c|}
\hline \multicolumn{1}{|c|}{ Construct } & Composite reliability & AVE \\
\hline Structural Social Capital & 0,913 & 0,840 \\
\hline Relational Social Capital & 0,913 & 0,681 \\
\hline Cognitive Social Capital & 0,827 & 0,710 \\
\hline Knowledge Acquisition & 0,963 & 0,811 \\
\hline
\end{tabular}

Finally, Barclay, Higgins and Thompson (1995) pointed out that for discriminant validity, a variable must share more variance with its indicators than with others variables in the model. In this line, we compared the square root of the AVE of each variable with the correlations between constructs. We can observe in table 2 that the square root of AVE (the diagonal in tables 3 and 4) is greater than the correlation between constructs (the off-diagonal data in tables 3 and 4), so we can affirm that each construct relates more strongly to its own measures than others. Hence we can say that we have a good model of measurement in both cases.

Table 3. Discriminant validity inside clusters

\begin{tabular}{|l|c|c|c|c|}
\hline & SCC & RSC & CSC & Knowledge \\
\hline Structural Social Capital & $\mathbf{0 , 8 9 4}$ & & & \\
\hline Relational Social Capital & 0.558 & $\mathbf{0 , 8 2 9}$ & & \\
\hline Cognitive Social Capital & 0.422 & 0.488 & $\mathbf{0 , 8 8 8}$ & \\
\hline Knowledge Acquisition & 0.383 & 0.447 & 0.553 & $\mathbf{0 , 8 6 9}$ \\
\hline
\end{tabular}

Table 4. Discriminant validity outside clusters

\begin{tabular}{|l|c|c|c|c|}
\hline & SCC & RSC & CSC & Knowledge \\
\hline Structural Social Capital & $\mathbf{0 , 9 1 6}$ & & & \\
\hline Relational Social Capital & 0.684 & $\mathbf{0 , 8 2 5}$ & & \\
\hline Cognitive Social Capital & 0.545 & 0.596 & $\mathbf{0 , 8 4 3}$ & \\
\hline Knowledge Acquisition & 0.671 & 0.593 & 0.490 & $\mathbf{0 , 9 0 1}$ \\
\hline
\end{tabular}

\subsection{Structural model}

\section{$\underline{\text { Inside industrial clusters }}$}

In order to test the structural model we examined size and significance of the path coefficients and the $\mathrm{R}^{2}$ values of the dependent variable. In the case of firms located in industrial clusters, we observed in figure 1 that structural social capital has a positive and significant effect on 
knowledge acquisition $(\beta=0.383 ; \mathrm{p}<0.001)$. Likewise this dimension influences the other two dimensions of social capital, so we can observed in both cases a positive and significant effect in the case of relation social capital $(\beta=0.558 ; \mathrm{p}<0.001)$ and in the case of cognitive social capital $(\beta=0.422 ; p<0.001)$. In this model structural social capital explain 14.8 percent of the total variance of the knowledge acquisition.

When we introduce in the model the effect of relational and cognitive social capital on knowledge acquisition we observe that the initial direct effect of structural social capital on knowledge acquisition disappeared. However relational $(\beta=0.196 ; p<0.05)$ and cognitive social capital $(\beta=0.436 ; \mathrm{p}<0.001)$ show a positive and significant effect on the dependent variable. That means that relational and cognitive social capital wholly mediates the relationship between structural social capital and knowledge acquisition. Thus, we can accept hypothesis 1, since in the case of firms inside the industrial clusters, structural social capital only exerts an indirect effect on knowledge acquisition through the relational and cognitive dimension of social capital. This indirect effect can be calculated multiplying the significant structural paths. In this case this indirect effect has a value of 0.109 through the relational social capital and 0.184 through cognitive social capital, so we obtain a total indirect effect of structural social capital on knowledge acquisition of 0.288 . In this case the model, we observed a significant change of $\mathrm{R}^{2}$ since now this model explains 36 percent of the total variance of the dependent variable. While relational social capital explains only the 8 percent of this variance of knowledge acquisition, cognitive social capital explain the 26 percent.

Figure 1. Structural model firms inside clusters $* * \mathrm{p}<0.05 ; * * * \mathrm{p}<0.01 ; * * * * \mathrm{p}<0.001$

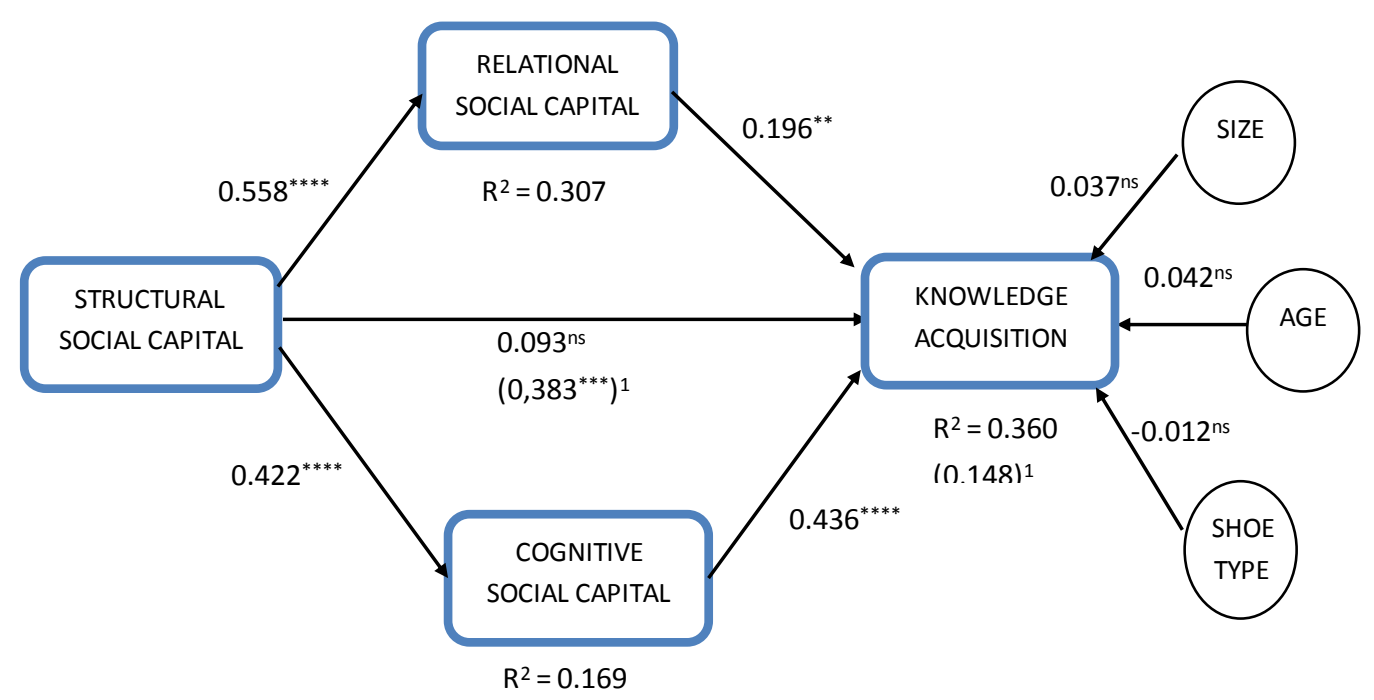


${ }^{1}$ Value without the intermediate variables in parenthesis

\section{$\underline{\text { Outside industrial clusters }}$}

In the case of firms located outside the industrial clusters, we observed in figure 2 that structural social capital has a positive and significant effect on knowledge acquisition $(\beta=0.660 ; \mathrm{p}<0.001)$. Furthermore this dimension influences the other two dimensions, so we can observed a positive and significant effect on relational social capital $(\beta=0.684 ; p<0.001)$ and a positive and significant effect on cognitive social capital $(\beta=0.545 ; \mathrm{p}<0.001)$. In this model structural social capital explain a high percent (45.5) of the total variance of the knowledge acquisition.

Figure 2. Structural model firms outside clusters

$* \mathrm{p}<0.1 ; * * \mathrm{p}<0.05 ; * * * \mathrm{p}<0.01 ; * * * \mathrm{p}<0.001$

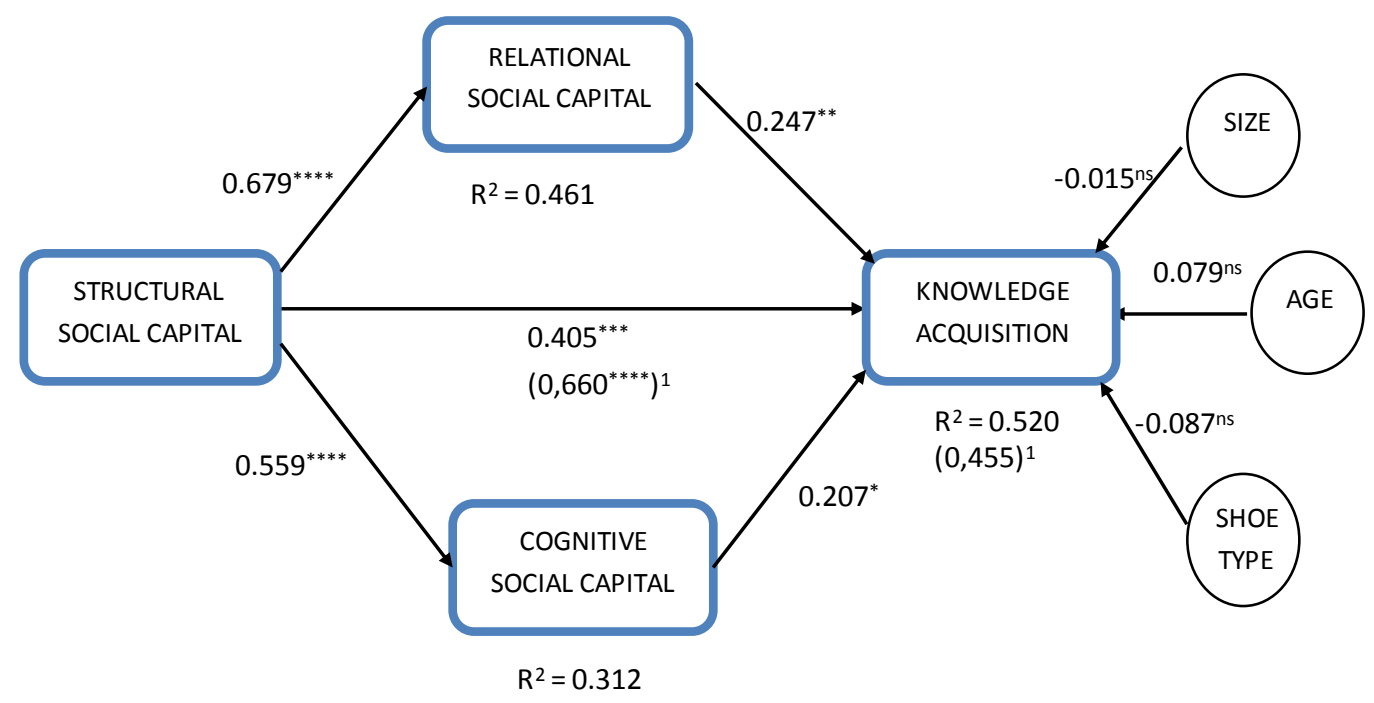

${ }^{1}$ Value without the intermediate variables in parenthesis

When we introduce in the model the effect of relational and cognitive dimensions of social capital on knowledge acquisition we observe that the initial direct effect of structural social capital is reduced but not eliminated $(\beta=0.405 ; \mathrm{p}<0.01)$. Relational social capital exerts a positive and significant effect on knowledge acquisition $(\beta=0.247 ; \mathrm{p}<0.05)$ and cognitive 
social capital in the same way shows a positive and significant effect $(\beta=0.207 ; \mathrm{p}<0.1)$. That means that relational and cognitive social capital partially mediates the relationship between structural social capital and knowledge acquisition. Thus, we can accept hypothesis 2, since in the case of firms outside the industrial clusters, structural social capital exerts a direct and an indirect effect on knowledge acquisition through the relational and cognitive dimensions. In this case the model explains 52 percent of the total variance of the dependent variable. Structural social capital explains the 27 percent of this variance of knowledge acquisition, relational social capital explains the 14 percent and cognitive social capital the 10 percent.

\section{DISCUSSION}

This research explores the relevance of structural social capital on knowledge acquisition as well as the role of relational and cognitive dimensions of social capital play as mediating variables in this relationship. In this line, we analyze and contrast the different effects that of these variables have on knowledge acquisition on two different samples -one sample of agglomerated companies and other sample of non-agglomerated companies- in the footwear industry.

First, we corroborate the high interrelation between the three dimensions of social capital. Thus, in both cases -firms inside cluster and firms outside cluster- we observe a strong effect of structural social capital on the relational and cognitive dimensions. Thus, according to the established in the literature, we confirm the importance of belonging to a dense network with strong links in order to promote trust between the contacts and the creation of shared values and common culture between them.

Findings show that relational and cognitive social capital becomes much more relevant in firms located in an industrial cluster than in firms outside clusters in order to acquired knowledge. The results show that in firms inside cluster the direct effect of structural social capital on knowledge acquisition disappears by introducing the relational and cognitive dimensions of social capital. That means that in agglomerated firms density and strength by itself don't allow companies to acquire external knowledge. Thus, these companies only will access external knowledge if they take advantage of density and strength of the network to promote trust, common goals and values between their contacts. 
As we noted above, the disadvantages of an excessive density -redundant information, lockin, myopia- are accentuated in agglomerated firms due to the own characteristics of clusters. This premise is supported by the results we show in table 5 and 6 . As we can observe, firms in industrial clusters have more structural social capital than firms outside industrial clusters. Thus, industrial clusters firms present more strength in their ties and show a higher density in their networks of contacts. Furthermore, we can observe that firms inside industrial clusters have the majority of their relationships with inner agents of industrial clusters and, moreover, they present higher level of relationships with this kind of agents than firms outside industrial clusters. On the contrary, firms outside industrial clusters show more relationships with agents outside of their locality than firms inside industrial clusters.

Table 5. ANOVA: Local relationships and outside locality

$\mathrm{N}=220 \quad * \mathrm{p}<0,10 ; * * \mathrm{p}<0,05 ; * * * \mathrm{p}<0,01 ; * * * * \mathrm{p}<0,001$

\begin{tabular}{|l|c|c|c|c|c|}
\hline Construct & $\begin{array}{c}\text { Levene } \\
\text { statistic }\end{array}$ & $\begin{array}{c}\text { Inside } \\
\text { clusters }\end{array}$ & $\begin{array}{c}\text { Outside } \\
\text { clusters }\end{array}$ & Welch & $\begin{array}{c}\text { Brown- } \\
\text { Forsythe }\end{array}$ \\
\hline $\begin{array}{l}\text { Relationships } \\
\text { local agents }\end{array}$ & $2,749^{* *}$ & 5,46 & 4,02 & $26,933^{* * * *}$ & $26,933^{* * * *}$ \\
\hline $\begin{array}{l}\text { Relationships agents } \\
\text { outside locality }\end{array}$ & $0,031^{\mathrm{ns}}$ & 3,85 & 4,42 & \multicolumn{2}{|c|}{$3,699^{*}$} \\
\hline
\end{tabular}

Table 6. Equality means contrast: structural social capital $\mathrm{N}=224 \quad * \mathrm{p}<0,10 ; * * \mathrm{p}<0,05 ; * * * \mathrm{p}<0,01 ; * * * * \mathrm{p}<0,001$

\begin{tabular}{|c|c|c|c|c|c|c|}
\hline \multirow{2}{*}{ Constructo } & \multicolumn{2}{|c|}{ Inside clusters } & \multicolumn{2}{|c|}{ Outside clusters } & \multirow{2}{*}{ Welch } & \multirow{2}{*}{$\begin{array}{l}\text { Brown- } \\
\text { Forsythe }\end{array}$} \\
\hline & $\bar{X}$ & $\sigma$ & $\bar{X}$ & $\sigma$ & & \\
\hline Frequent relationships & 5,21 & 1,39 & 4,74 & 1,60 & $3,730 *$ & $3,730 *$ \\
\hline Know in a personal way & 5,31 & 1,38 & 4,98 & 1,70 & 1,633 & 1,633 \\
\hline Close relationships & 4,14 & 1,51 & 3,28 & 1,84 & $9,865^{* * *}$ & $9,865^{* * *}$ \\
\hline Strong ties & 4,89 & 1,21 & 4,33 & 1,44 & $6,491 * *$ & $6,491 * *$ \\
\hline $\begin{array}{l}\text { Exchange similar } \\
\text { information }\end{array}$ & 4,45 & 1,35 & 4,00 & 1,57 & $3,623 *$ & $3,623^{*}$ \\
\hline Contacts know each other & 4,40 & 1,49 & 3,94 & 1,65 & $3,210 *$ & $3,210 *$ \\
\hline $\begin{array}{l}\text { Contacts who give } \\
\text { information are related to } \\
\text { each other }\end{array}$ & 4,04 & 1,42 & 3,67 & 1,69 & 2,091 & 2,091 \\
\hline Density & 4,30 & 1,34 & 3,87 & 1,43 & $3,938 *$ & $3,938 *$ \\
\hline
\end{tabular}




\begin{tabular}{|l|r|r|r|r|r|r|}
\hline Structural social capital & 4,59 & 1,04 & 4,10 & 1,33 & $6,120 * *$ & $6,120 * *$ \\
\hline
\end{tabular}

In industrial clusters the relevance of cognitive and relational social capital is reflected in the increase of $\mathrm{R}^{2}$, which is increased from 0.148 in the model that only considers the structural social capital to 0.360 in the model that considers the three dimensions. So the inclusion of relational and cognitive social capital allows an increase of 0.212 . Also, we can indicate that in this case the indirect effect that structural capital exerts through cognitive social capital is higher than that exerted through the relational social capital. This highlights that cognitive social capital explains 26 percent of the variance of knowledge acquisition (36\%). Thus, we can highlight the importance of developing shared norms and values and a common culture taking advantage of the density and strength of the network, to acquire external knowledge in industrial clusters.

On the other hand, in companies outside industrial clusters, we highlight the important role of structural capital in the acquisition of external knowledge. So, even when we introduce in the model the relational and cognitive dimensions of social capital, although the indirect effect through these dimensions is significant, the direct effect of structural social capital remains significant. This dimension exerts the greatest influence on knowledge acquisition. This relevance can be observed in two aspects: first, in this case structural social capital is the variable with the greatest explanatory power because it explains $27 \%$ of the explained variance (52\%); second, the variance of knowledge acquisition only increases 6.5 percent when we consider the effect of the other two dimensions.

Thus, we corroborate our initial assumption since we observed that the effect of the structural social capital on knowledge acquisition will be different depending on the degree of agglomeration or the degree of geographical proximity. In firms that belonging to an industrial cluster, the disadvantages of density excess and strength of ties are more evident because most of their contacts are internal and therefore the degree of redundancy in the information is higher. However, structural social capital appears as the key dimension to access external knowledge for companies outside clusters.

Finally, we observe that in firms outside clusters, social capital explains a higher percentage of the variance of knowledge acquisition that in firms inside clusters. This highlights the relevance for firms outside clusters to strengthen their networks of relationships, and mainly 
the density and strength in the relationships with their contacts in order to access to the external knowledge.

\section{CONCLUSION, LIMITATIONS AND FUTURE RESEARCH}

In geographic agglomerations of firms, the density and strength of the ties between firms only generate greater knowledge acquisition if they are focus on developing greater trust and shared values and goals with their contacts. It can say that clustered firms suffer from the network paradox related to the information redundancy, block-in, isolating and myopia that impede direct access to valuable external knowledge from social structural capital. Therefore, findings provide new empirical evidence on the adverse effect of excess density and strength of the ties for new and valuable knowledge in contexts of geographic proximity. The cognitive dimension of social capital showed greatest impact on knowledge acquisition between companies belonging to the cluster. It seems that in contexts of geographical agglomerations of firms is the convergence of values, mission and culture the key elements to explain the exchange and acquisition of relevant knowledge.

However, in geographically disperse contexts, findings support the importance of creating dense and strong networks for firms in accessing valuable external knowledge. Geographic distance avoids potential drawbacks of excessive structural social capital to acquire external knowledge. Among firms located outside cluster, the direct effect of density and strength of the networks on the acquisition of knowledge is complemented by the indirect effect through trust and shared values and goals with contacts. For all three dimensions of social capital, they explained better knowledge acquisition between companies outside than inside the clusters. In fact, for external firms the knowledge acquisition was explained by more than $50 \%$ of the variance.

The empirical study contributes to a better understanding of implications of geographical proximity specifically belonging or not to an industrial cluster, on the differences in the relationship between social capital and knowledge acquisition.

With this research we contribute question where and how the social capital and knowledge acquisition is associated. We provide to the cluster literature (Porter, 1990; Becatini, 1990) a better contextualization and understanding of the controversial relationship between the structural social capital and knowledge acquisition. In fact, geographical proximity helps to 
understand how density and strong of ties lead to external valuable knowledge, comparing firms inside and outside clusters

We also contribute to consolidate the inter-organizational approach to social capital theory in order to understand how and in which context the social capital dimensions are interrelated, going further to the an intra-organizational approach (Tsai and Ghoshal, 1998). Thus, we connect social capital and cluster perspectives to analyze how firms can acquire valuable knowledge from their networks, overcoming the gap of the literature on how this process occurs inside and outside the clusters.

The results allow us to suggest some recommendations for both, companies and institutions in mature industries such as footwear industry. Companies should address the development of social relationships to acquire valuable knowledge exploiting advantages of the geographic proximity to their contacts. Companies belonging to a cluster should assess potential concerns deriving from arising redundancy and internal closure and an over density and strength of the ties with their contacts. To avoid these problems and be able to access relevant external knowledge these companies should take advantage of cohesion of its network and the strength of their ties to build trust and, above all, shared values and goals with their contacts.

Institutions located in the clusters should solve problems arising from the combination of geographic proximity and density of networks and reinforce the process that allows companies to access new and relevant information for decision-making. However, companies located outside of a cluster should balance the geographical dispersion of contacts, accessing dense networks with strong links as the primary mechanism to acquire new external knowledge. However, they have to reinforce this mechanism aligning such networks to strengthen trust and shared goals with contacts.

We have to assume a number of limitations to the development of the study. First, the empirical analysis was carried out in an industry characterized to be mature and territorially embedded, such as footwear, and therefore, we must be caution in generalizing the findings to other industries. Moreover, the study is cross-cutting, due to the difficulty of longitudinal studies on these particular complex conceptualizations, as dimensions of social capital and the acquisition of knowledge. Finally, in spite of the significant effort made to ensure the robustness of the analysis including validity tests, some biases cannot be avoided. 
The results suggest new lines of research to complement the approach of the study. First, it would be interesting to extend the analysis of the impact of the interrelationships of the dimensions of social capital on other variables related to corporate behavior, as radical or incremental innovation and entrepreneurial orientation and to firm performance. We also considered interesting to study the interaction of different internal and external dimensions of social capital, looking for complementary relationships between them. On the other hand, we aim to address the hypothesized in this study in contexts of high-tech industries, where relations between the dimensions of social capital and its impact on the acquisition of new knowledge can be differently configured. Finally, in a complementary manner, we also propose the study of the interrelationships of the dimensions of capital suggested by Putnam (1993) -bridging and bonding capital, linked with internal and external relationships to clusters, on the acquisition of knowledge.

\section{REFERENCES}

Adler, P. and Kwon, S. (2002): "Social capital: prospects for a new concept" Academy of Management Review, 27(1), 17-40.

Ahuja, G. (2000): "Collaboration networks, structural holes and innovation: a longitudinal study”, Administrative Science Quarterly, 45(3), 425-453.

Armstrong, J.S. and Overton, T. (1977): "Estimating nonresponse bias in mail surveys", Journal of Marketing Research, 14, 396-402.

Audretsch, D. (1998): "Agglomeration and the location of economic activity", Oxford Review of Economic Policy, 14, 18-29.

Barclay, D.; Higgins, C. and Thompson, R. (1995): "The Partial Least Squares (PLS) Approach to Causal Modelling: Personal Computer Adoption and Use as an Illustration", Technology Studies, Special Issue on Research Methodology, 2(2), 285-309.

Barney, J. and Hansen, M. (1994): "Trustworthiness as a source of competitive advantage", Strategic Management Journal, 15, 175-190.

Bathelt, H.; Malmberg, A. and Maskell, P. (2004): "Cluster and knowledge: local buzz, global pipelines and the process of knowledge creation", Progress in Human Geography, 28(1), $31-56$.

Becattini, G. (1979) "Dal settore industriale al distretto industriale. Alcune considerazioni sull'unita di indagine dell'economia industriale", Rivista di Economia e Politica Industriale, $5(1), 7-21$.

Becattini, G. (1990): "The marshallian industrial district as a socio-economic notion". In F. Pyke, G. Becattini, and W. Sengenberger (eds) Industrial Districts and Inter-firm Cooperation in Italy, 37-51.Geneva: International institute for Labour Studies. 
Bhattacharya, R., Devinney, T. M., and Pillutla, M. M. (1998): "A formal model of trust based on outcomes". Academy of Management Review, 23(3), 459-472.

Boari, C. and Lipparini, A. (1999): "Networks within industrial districts: organising knowledge creation and transfer by means of moderate hierarchies", Journal of Management and Governance, 3(4), 339-360.

Boland, R.J., and R.V. Tenkasi. (1995): "Perspective making and perspectiva taking in the communities of knowing". Organization Science, 6, 350-372.

Bolino, M. C.; Turnley, W.H. and Bloodgood, J.M. (2002): "Citizenship behaviour and the creation of social capital in organisation", Academy of Management Review, 27(4), 505-522.

Boschma, R. and Frenken, K. (2006): "Why is economic geography not an evolutionary science? Towards an evolutionary economic geography", Journal of Economy Geography, 6(3), 273-302.

Boschma, R.and ter Wall, A. (2007): "Knowledge networks and innovative performance in an industrial district. The case of a footwear district in the south of Italy", Industry and Innovation, 14(2), 177-199.

Boix, R. and Galletto, V. (2006): "Sistemas locales de trabajo y distritos industriales marshallianos en España", Economía Industrial, 359,165-184.

Bremmers, H., Omta, O., Kemp, R., and Haverkamp, D. J. (2007): 'Do stakeholder groups influence environmental management system development in the Dutch agri-food sector?" Business strategy and the Environment, 16(3), 214-231.

Brenner, T. (2001): Geographical proximity and technological spillovers between industries, Max-Planck institute, Jena, mimeo.

Breschi, S. and Lissoni, F. (2001): "Knowledge Spillovers and Local Innovation Systems: A Critical Survey", Industrial and Corporate Change, 10(4), 975-1005.

Burt, R. S. (1992): Structural holes: The social structure of competition, Harvard University Press: Cambrige, MA.

Butler, B. And Purchase, S. (2008): "Use of social capital among Russian managers of a new generatio", Industrial Marketing Management, 37(5), 531-538.

Seibert, S.; Kraimer, M. and Liden, R. (2001): "A social capital theory of career success", Academy of Management, 44(2), 219-237.

Carey, S., Lawson, B. and Krause, D.R. (2011): "Social capital configuration, legal bonds and performance in buyer-supplier relationships". Journal of Operations Management, 29(4), 277-288.

Carmines, E.G. and Zeller, R.A. (1979): "Reliability and validity assessment", Sage University Paper Series on Quantitative Applications in the Social Sciences, N.07-017. Beverly Hills, CA: Sage.

Carson, S.J., Madhok, A., Varman, R. and John G. (2003): "Information processing moderators of the effectiveness of trust-based governance in interfirm R\&D collaboration". Organization Science, 14(1), 45-56.

Castro, I. and Roldan, J.L. (2013): "A mediation model between dimensions of social capital”, International Business Review, 22(6), 1034-1050. 
Chen, C. and Huang, J. (2009): "Strategic human resource practices and innovation performance - The mediating role of knowledge management capacity", Journal of Business Research, 62(1), 104-114.

Chin, W.W. (1998a): "Issues and opinion on structural equation modeling", MIS Quarterly, 22(1), 7-15.

Chiu, C. M., Hsu, M. H., and Wang, E. T. (2006): "Understanding knowledge sharing in virtual communities: An integration of social capital and social cognitive theories". Decision Support Systems, 42(3), 1872-1888.

Coff, R. W., and Blyler, M. (2003): 'Dynamic capabilities, social capital, and rent appropriation: Ties that split pies". Strategic Management Journal, 24, 677-686.

Coleman, J.S. (1990): Foundations of Social Theory. Harward University Press: Cambridge, MA.

Correia, I. and Petiz, O. (2007): 'Firms and universities, do spillovers enhance firm's performance?" International Entrepreurship and Management Journal, 3(2), 145-157.

DeCarolis, D.M. and Deeds, D.L. (1999): "The impact of stocks and flows of organizational knowledge on firm performance: an empirical investigation of the biotechnology industry", Strategic Management Journal, 20(10), 953-968.

Doz, Y.L. (1996): "The evolution of cooperation in strategic alliances: initial conditions or learning processes?” Strategic Management Journal, 17 (summer special issue), 55-84.

Dyer, J. and Nobeoka, K. (2000): "Creating and managing a high-performance knowledgesharing network: the toyota case", Strategic Management Journal, 21, 345-367.

Dyer, J. and Singh, H. (1998): "The relational view: cooperative strategy and sources of interorganizational competitive advantage", Academy of Management Review, 23, 4, 660679.

Eapen, A. (2012): "Social structure and technology spillovers from foreign to domestic firms". Journal of International Business Studies, 43(3), 244-263.

Fawcett, S.E., Ellram, L.M. and Ogden, J.A. (2006), Supply Chain Management: From Vision to Implementation, Prentice Hall, Upper Saddle River, NJ.

Fornell, C. and Larcker, D.F. (1981): "Evaluating Structural Equation Models with Unobservable Variables and Measurement Error", Journal of Marketing Research, 18, Februay: 39-50.

Gabarro, J.J. (1978): "The development of trust, influence, and expectations". In A. G. Athos \& J.J.Gabarro (Eds.), Interpersonal behavior: Communication and understanding in relationships: 290-303. Englewood Cliffs, NJ: Prentice Hall.

Gargiulo, M., and Benassi, M. (2000): "Trapped in your own net? Network cohesion, structural holes, and the adaptation of social capital". Organization science, 11(2), 183-196.

Giuliani, E. (2007): "The selective nature of knowledge networks in clusters: evidence from the wine industry", Journal of Economic Geography, 7(2), 139-168.

Giuliani, E. (2011). "Role of technological gatekeepers in the growth of industrial clusters: Evidence from Chile". Regional Studies, 45(10), 1329-1348. 
Giuliani, E. and Bell, M. (2005): "The micro-determinants of meso-level learning and innovation: evidence from a Chilean wine cluster", Research Policy, 34(1), 47-68.

Gulati, R. (1995): "Does familiarity breed trust? The implications of repeated ties for contractual choice in alliances", Academy of Management Journal, 38, 85-112.

Gulati, R., and Gargiulo, M. (1999): "Where do interorganizational networks come from?" American Journal of Sociology, 104(5), 1439-1493.

Granovetter, M.S. (1973): "The strength of weak ties", American Journal of Sociology, 78, 1360-1380.

Granovetter, M.S. (1985): "Economic action and social structure: the problem of embeddedness". American Journal of Sociology, 91, 481-510.

Granovetter, M. S. (1992): "Problems of explanation in economic sociology", en Nohria, N. and Eccles, R. (eds): Networks and organizations: structure, form an action, 25-56. Harvard business school press. Boston.

Greve, A. and Salaff, J.W. (2003): "Social networks and entrepreneurship", Entrepreneurship theory and practice, 28(1), 1-22.

Gulati, R.; Nohria, N. and Zaheer, A. (2000): "Strategic networks", Strategic Management Journal, 21(3), 203-215.

Håkansson, H., and Ford, D. (2002): "How should companies interact in business networks?" Journal of Business Research, 55(2), 133-139.

Hervas-Oliver, J.L. and Albors-Garrigos, J. (2012) The Role of a Firm's Absorptive Capacity and the Technology Transfer Process in Clusters: How Effective Are Technology Centres in Low-Tech Clusters? Entrepreneurship and Regional Development 24, 7-8, 523-559.

Hsu, J.S. and Hung, Y.W. (2013): "Exploring the interaction effects of social capital", Information \& Management, 50(7), 415-430.

Huber, G.P. (1991): "Organizational learning: the contributing processes and the literatures", Organization Science, 2(1), 88-115.

Hulland, J. (1999): "Use of partial least squares (PLS) in strategic management research: A review of four recent studies," Strategic Management Journal, 20(2), 195-204.

Inkpen, A. and Tsang, E. (2005): "Social capital, networks, and knowledge transfer", Academy of Management Review, 30(1), 146-165.

Jaffe, A.B.; Trajtenberg, M. and Henderson, R. (1993): "Geographic localization of knowledge spillovers as evidenced by patent citations", Quarterly journal of economics, 108(3), 577-598.

James, L.R., Mulaik, S.A. and Brett, J.M. (2006). A tale of two methods. Organizational Research Methods, 9(2), 233-244.

Kale, P.; Singh, H.; Pelmutter, H. (2000): "Learning and protection of proprietary assets in strategic alliances: building relational capital", Strategic Management Journal, 21(3), 217237.

Knoben, J., and Oerlemans, L. A. (2006): "Proximity and inter-organizational collaboration: A literature review". International Journal of Management Reviews, 8(2), 71-89. 
Kohtamäki, M., Vesalainen, J., Henneberg, S., Naudé, P., and Ventresca, M. J. (2012): "Enabling relationship structures and relationship performance improvement: The moderating role of relational capital". Industrial Marketing Management, 41(8), 1298-1309.

Koka, B. and Prescott, J. (2002): "Strategic alliances as social capital: a multidimensional view", Strategic of Management Journal, 23(9), 795-816.

Krugman, P. (1991): Geography and trade. MIT Press, Cambridge, MA.

Lane, P.J.; Salk, J.E. and Lyles, M.A. (2001): "Absorptive capacity, learning and performance in international joint ventures", Strategic Management Journal, 22, 1139-1161.

Lane, P.J. and Lubatkin, M. (1998): "Relative absorptive capacity and interorganizational learning", Strategic Management Jounal, 19, 461-477.

Lazerson, M.H. and Lorenzoni, G. (1999): "The firms that feed industrial districts: a return to the Italian source", Industrial and Corporate Change, 8(2), 235-266.

LeSage, J. P. and Fischer, M. M. (2012): "Estimates of the impact of static and dynamic knowledge spillovers on regional factor productivity". International Regional Science Review, 35(1), 103-127.

Leuthesser, L. (1997): "Supplier relational behavior: An empirical assessment". Industrial marketing management, 26(3), 245-254.

Li, J.J., Poppo, L. and Zhou, K.Z. (2010): "Relational mechanisms, formal contracts, and local knowledge acquisition by international subsidiaries", Strategic Management Journal, 31(4), 349-370.

Li, Y., Ye, F., and Sheu, C. (2014): "Social capital, information sharing and performance: Evidence from China". International Journal of Operations \& Production Management, 34(11), 1440-1462.

Lissoni, F. (2001): "Knowledge codification and the geography of innovation: the case of Brescia mechanical cluster", Research Policy, 30(9), 1479-1500.

Lorenzen, M. (2007): "Social capital and localised learning: proximity and place in technological and institutional dynamics". Urban Studies, 44(4), 799-817.

Mael, F. A., and Ashforth, B. E. (1995): "Loyal from day one: Biodata, organizational identification, and turnover among newcomers". Personnel Psychology, 48(2), 309-333.

Marshall, A. (1890): Principles of Economic, MacMillan, London.

Maula, M.; Autio, E. and Murray, G. (2003): "Prerequisites for the creation of social capital and subsequent knowledge acquisition in corporate venture capital", Venture Capital, 35(2), 117-134.

McEvily, B. and Zaheer, A. (1999): "Bridging ties: a source or firm heterogeneity in competitive capabilities", Strategic Management Journal, 20, 1133-1156.

Molina F.X. (2005a): "The territorial agglomerations of firms: a social capital perspective from the Spanish tile industry", Growth and Change, 36(1), 74-99.

Molina, F.X. and Ares, M.A. (2007): "Factores inhibidores de la relocalización de actividades en los distritos industriales. El caso de la cerámica de Castellón”, Cuadernos de Estudios Empresariales, 17, 9-30. 
Molina-Morales, F.X., and Expósito-Langa, M. (2012): "The impact of cluster connectedness on firm innovation: R\&D effort and outcomes in the textile industry". Entrepreneurship \& Regional Development, 24(7-8), 685-704.

Molina-Morales, F. X., and Martínez-Fernández, M. T. (2008): "Shared resources in industrial districts: Information, know-how and institutions in the Spanish tile industry". International Regional Science Review, 31(1), 35-61.

Molina-Morales, F.X. and Martinez-Fernandez, M. T. (2009): "Too much love in the neighborhood can hurt: how an excess of intensity and trust in relationships may produce negative effects on firms", Strategic Management Journal, 30: 1013-1023.

Molina-Morales, F.X., Martínez-Fernández,T. and Coll-Serrano, V. (2012): 'La eficiencia y la innovación en las subredes de empresas. Un estudio del distrito cerámico español". Innovar, 24(46), 109-126.

Morrison, A. and Rabellotti, R. (2005): "Knowledge and information networks: evidence from an italian wine local system", Working Paper 174/2005. CESPRI, Universitá Bocconi, Milano.

Mowery, D.C.; Oxley, J.E. and Silverman, B.S. (1996): "Strategic alliances and inter-firm knowledge transfer", Strategic Management Journal, 17, 77-92.

Munari, F., Sobrero, M., and Malipiero, A. (2012): "Absorptive capacity and localized spillovers: focal firms as technological gatekeepers in industrial districts". Industrial and Corporate Change, 21(2), 429-462.

Muscio, A. (2006): "Patterns of innovation in industrial districts: an empirical analysis", Industry and Innovation, 13(3), 291-312.

Nahapiet, J. and Ghoshal, S (1998): "Social capital, intellectual capital, and the organizational advantage", Academy of Management Review, 23(2), 242-266.

Nunnally, J. (1978): Psychometric theory. $2^{\mathrm{a}}$ ed. McGraw-Hill. New York.

Owen-Smith, J., and Powell, W. (2004): "Knowledge networks in the Boston biotechnology community." Organization Science, 15, 5-21.

Paniccia, I. (1998): "One, a hundred, thousands of industrial district. Organizational variety in local networks of small and medium-sized enterprises", Organization Studies, 19(4), 667699.

Parra-Requena, G., Molina-Morales, F. X., and Garcia-Villaverde, P. (2010): "The mediating effect of cognitive social capital on knowledge acquisition in clustered firms". Growth and change, 41(1), 59-84.

Parra-Requena, G., Ruiz-Ortega, M. J., and Garcia-Villaverde, P. M. (2013): "Social Capital and Effective Innovation in Industrial Districts: Dual Effect of Absorptive Capacity". Industry and Innovation, 20(2), 157-179.

Porter, M. (1998): "Cluster and the Economics of Competition", Harvard Business Review, 76(6), 77-91.

Pulles, N, and Schiele, H. (2013): "Social capital determinants of preferential resource allocation in regional clusters", Management Revue, 24(2), 96-113. 
Putnam, R.D. (1993): Making Democracy Work: civic traditions in Modern Italy. Princeton University Press. Princeton.

Rampersad, G.; Quester, P. and Troshani, I. (2010): "Managing innovation networks: Exploratory evidence from ICT, biotechnology and nanotechnology networks", Industrial Marketing Management, 39(5), 793-805.

Rosenkopf, L. and Almeida, P. (2003): "Overcoming local search through alliances and mobility”, Management Science, 49 (6), 751-766.

Rowley, T.; Behrens, D. and Krackhardt, D. (2000): "Redundant governance structures: An analysis of structural and relational embeddedness in the steel and semiconductor industries". Strategic Management Journal, 21, 369-386.

Ruiz-Ortega, M. J., Parra-Requena, G., and García-Villaverde, P. M. (2013): "Do Territorial Agglomerations Still Provide Competitive Advantages? A Study of Social Capital, Innovation, and Knowledge”. International Regional Science Review, 0160017613512652.

Simonin, B.L (1999): "Ambiguity and the process of knowledge transfer in strategic alliances", Strategic Management Journal, 20(7), 595-623.

Spanos, Y.E.and Lioukas, S. (2001): "An examination into the causal logia of retn generation: contrasting Porter's competitive strategy framework and the resource based perspective", Strategic Management Journal, 22, 907-934.

Tallman, S.; Jenkins, M.; Henry, N. and Pinch, S. (2004): "Knowledge, clusters, and competitive advantage", Academy of Management Review, 29(2), 258-271.

Teece, D.; Pisano, G. and Shuen, A. (1997): "Dynamic capabilities and strategic management", Strategic Management Journal, 18(7), 509-533.

Tsai, W. and Ghoshal, S. (1998): "Social capital, and value creation: the role of intrafirm networks". Academy of Management Journal, 41, 464-478.

Utterbact, J. (1974): "Innovation in industry and the diffusion of technology", Science, 183, 620-626.

Uzzi, B. (1996): "The sources and consequences of embeddedness of the economic performance of organizations: The network effect", American Sociological Review, 61(4), 674-698.

Villena, V.; Revilla, E. and Choi, T. (2011): "The dark side of buyer-supplier relationships: A social capital perspective", Journal of Operations Management, 29 (6), 561-576.

Weber, B. and Weber, C. (2007): "Corporate venture capital as a mean or radical innovation: Relational fit, social capital, and knowledge transfer", Journal of Engineering and Technology Management, 24(1-2), 11-35.

Westerlund, M. and Svahn, S. (2008): "A relationship value perspective of social capital in networks of software SMEs", Industrial Marketing Management, 37(5), 492-501.

Yim, B., \& Leem, B. (2013): "The effect of the supply chain social capital". Industrial Management \& Data Systems, 113(3), 324-349.

Yli-Renko, H.; Autio, E. and Sapienza, H. (2001): "Social capital, knowledge acquisition, and knowledge expoitation in young technology-based firm" Strategic Management Journal, 22(6-7), 587-613. 
Young-Ybarra, D. and Wiersema, M. (1999): "Strategic flexibility in information technology alliances: the influence of transaction cost economics and social Exchange theory"; Organization Science, 10(4), 439-459. 